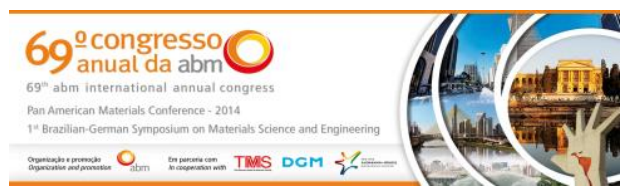

Tema: Materiais Cerâmicos, Compósitos e Poliméricos

\title{
COMPORTAMENTO À FADIGA EM CONTROLE POR TENSÃO DE MATERIAIS COMPÓSITOS CARBONO-EPÓXI*
}

\section{Resumo}

Priscilla Danielle de Oliveira Lopes Costa ${ }^{1}$ Gigliola Salerno²

$\mathrm{Na}$ indústria aeronáutica, fadiga é um dos processos mais importantes quando se considera o dano e a falha das estruturas de uma aeronave. Adicionalmente, os materiais compósitos apresentam altas resistência e rigidez específicas. No entanto, os mecanismos de dano de um material compósito são complexos. Como consequência, o objetivo deste trabalho é identificar as propriedades à fadiga de materiais compósitos de fibras de carbono e resina epóxi, com configuração de lâminas $0 \% 190^{\circ} \pm 45^{\circ}$ e caracterizar os mecanismos de dano quando estes são submetidos à fadiga. Para tanto, nos corpos de prova foram realizados ensaios de fadiga em uma máquina universal de ensaios MTS, em controle por tensão com frequência de $10 \mathrm{~Hz}$ com carregamentos máximos de 6000, 5000, 4000 e $3000 \mathrm{~N}$ e $R=0,1$ (tração-tração). O compósito em estudo demonstrou boa resistência à fadiga por controle de tensão, a vida infinita é de aproximadamente $48,5 \%$ da resistência à tração. O número de ciclos a fadiga depende da amplitude de tensão, assim como da tensão média, sendo que quanto menor a carga aplicada menor a amplitude de tensão (e a tensão média) e maior o número de ciclos a fratura. A fractografia após os ensaios caracterizou os mecanismos de dano durante o processo de fadiga, sendo que fratura na matriz, fratura das fibras e descolamento fibra/matriz são os mecanismos de falha dominantes durante a fadiga, através de análise por microscopia eletrônica de varredura.

Palavras-chave: Fadiga; Compósito laminado; Carbono-epóxi; Mecanismos de dano.

\section{CARBON EPOXY COMPOSITE MATERIAL FATIGUE BEHAVIOR UNDER TENSION CONTROL}

\section{Abstract}

Fatigue is the most important issue considering structural damage and fail of airplanes. Besides, composite materials have high specific strength and stiffness. However, damage is usually complex. As a consequence, the main purpose of this work is characterize fatigue behaviour of $0 \% / 90^{\circ} / \pm 45^{\circ}$ laminate configuration carbon epoxy and damage developed during fatigue process. Fatigue tests were carried on by universal tests machine MTS $250 \mathrm{kN}$ under tension control, $10 \mathrm{~Hz}$ frequency, $\mathrm{R}=0.1$ and maximum loadings about 6000, 5000, 4000 and $3000 \mathrm{~N}$. The outcomes were satisfactory; $48.5 \%$ of tensile strength resistance reached the infinite life (superior to $10^{6}$ cycles). The amplitude stress and mean stress provoked the decrease of fatigue life. The Scanning Electronic Microscopic demonstrated that the fibres fracture, matrix fracture and debounding fiber/matrix dominated the damage process.

Keywords: Fatigue; Composites; Carbon epoxy; Damage.

1 Estudante de Engenharia de Materiais, FEl, São Bernardo do Campo, SP, Brasil.

2 Engenheira mecânica, Dra., Professora, Engenharia de Materiais, FEl, São Bernardo do Campo, $S P$, Brasil.

\footnotetext{
* Contribuição técnica ao $69^{\circ}$ Congresso Anual da ABM - Internacional e ao 14ํㅡㄹ ENEMET - Encontro Nacional de Estudantes de Engenharia Metalúrgica, de Materiais e de Minas,21 a 25 de julho de 2014, São Paulo, SP, Brasil.
} 


\section{MATERIAIS E MÉTODOS}

O material compósito laminado (preparado no Laboratório de Materiais em projetos anteriores [9]) é formado por lâminas, as quais são compostas por fibras longas de carbono, na forma de um tecido, recobertas por uma matriz de resina epóxi. A configuração das lâminas são de $0^{\circ} / 90^{\circ}$ e $\pm 45^{\circ}$, representada pela Figura 1. Foram utilizados dez corpos no ensaio de fadiga por controle de tensão na máquina MTS 810 Material Test System, com capacidade de $250 \mathrm{kN}$, utilizando a frequência de 10 $\mathrm{Hz}$ e três ensaios com cargas máximas e mínimas de $(6000 \mathrm{~N}$ e $600 \mathrm{~N})$, (5000N e $500 \mathrm{~N}),(4000 \mathrm{~N}$ e $400 \mathrm{~N})$ e $(3000 \mathrm{~N}$ e $300 \mathrm{~N})$ para a configuração de lâminas $0 \% 90 \% 45^{\circ}$, segundo a norma ASTM D3479 [10].

\begin{tabular}{l|c|}
\cline { 2 - 2 } Camada 1 & $0^{\circ} / 90^{\circ}$ \\
\cline { 2 - 2 } Camada 2 & $-45^{\circ} / 45^{\circ}$ \\
\cline { 2 - 2 } Camada 3 & $-45^{\circ} / 45^{\circ}$ \\
\cline { 2 - 2 } Camada 4 & $0^{\circ} / 90^{\circ}$ \\
&
\end{tabular}

Figura 1. Sequência das camadas que compõem o compósito configuração de lâminas $0 \% 90^{\circ} \pm 45^{\circ}$ [9].

Os dez corpos de provas têm suas dimensões de $20 \times 200 \times 1,35 \mathrm{~mm}$. Em Rossini, 2012 foram produzidos os corpos de prova, a Figura 2 mostra a representação esquemática dos corpos de prova utilizados, segundo a norma ASTM D3039 [11].

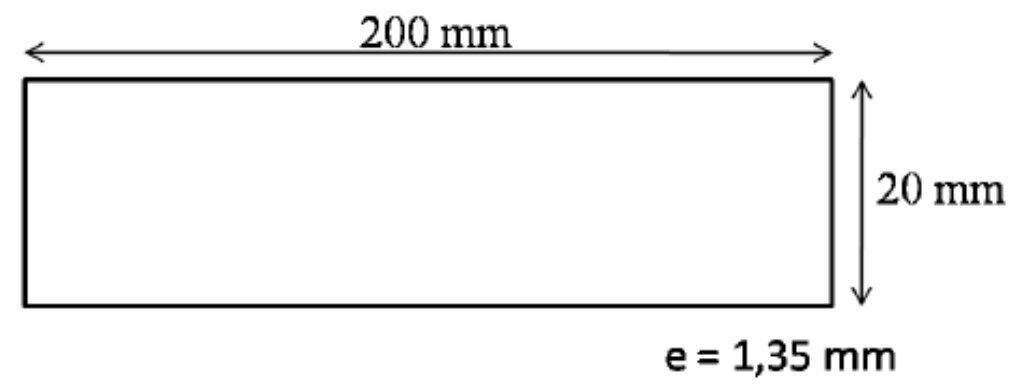

Figura 2. Representação esquemática das dimensões dos corpos de prova para o ensaio de fadiga por controle de tensão $\left(0^{\circ} / 90^{\circ} \% 45^{\circ}\right)$ de alto ciclo [9].

O fator chave na seleção da tolerância das amostras e métodos de agarramento à máquina de ensaios é a introdução bem sucedida da força para a amostra e a prevenção da falha prematura como resultado de uma significativa descontinuidade, deste modo há necessidade de se utilizar apoios nas amostras para o agarramento, para assim evitar uma falha indesejável e não significativa na área de contato da amostra com a garra da máquina. Os apoios utilizados para o ensaio são de alumínio com as dimensões de $20 \times 45 \times 2,0 \mathrm{~mm}$, assim como os corpos de prova sua largura, espessura e comprimento devem estar dentro das recomendações de tolerância dadas pela norma ASTM D3039 [11]. Os apoios são colados em cada amostra em suas extremidades com cola de resina epóxi (cura a frio), utilizando quatro apoios para cada uma das dez amostras a serem analisadas [11].

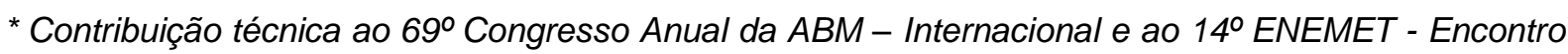
Nacional de Estudantes de Engenharia Metalúrgica, de Materiais e de Minas,21 a 25 de julho de 2014, São Paulo, SP, Brasil.
} 


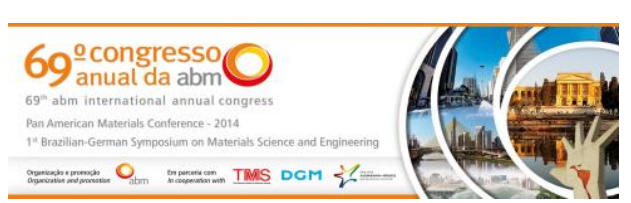

Após os ensaios, no microscópio eletrônico de varredura MEV é possível produzir imagens de alta ampliação e resolução das fibras do tecido. A partir da emissão e interação de feixes de elétrons sobre a amostra. No compósito, a matriz que é composta pela resina epóxi apresenta propriedades inferiores à fibra, assim, ela fratura primeiro sob solicitações mecânicas. O suporte às solicitações pelos componentes se dá pela fibra, portanto a adesão deve ser suficientemente forte para que a transferência de esforços seja eficiente e retarde os mecanismos de falha. A adesão é verificada no compósito, através das análises microscópicas obtidas pelo MEV.

Através da carga aplicada e da área da amostra se obtém a tensão aplicada, podendo obter a tensão média entre a máxima e mínima, assim como a amplitude de tensões. O número de ciclos é dado pelo programa da máquina de ensaios diretamente, e também gera várias tabelas, onde se tem valores de deformação máxima e mínima ao longo do ensaio, com essa tabela, encontra-se o mínimo e o máximo valor de deformação, de onde se consegue obter a deformação média e a amplitude de deformação para cada ensaio, sendo o procedimento de cálculos para as configurações de lâminas $0 \% 190^{\circ} \pm 45^{\circ}$.

\section{RESULTADOS E DISCUSSÃO}

Com os dados gerados nos ensaios pela MTS, foram traçados os gráficos (a) e (b) Figura 3, onde se observa que quanto maior a amplitude de tensão ou a tensão média, menor é o número de ciclos à fratura e que os ensaios para a carga de $5000 \mathrm{~N}$ geraram uma dispersão grande nos dados. Para os ensaios de $3000 \mathrm{~N}-$ $300 \mathrm{~N}$, a vida é considerada infinita, ultrapassando $10^{6}$ de ciclos. Resultados dos ensaios se encontram organizados na Tabela 2.

Após a retirada dos corpos de prova fraturados é possível identificar mecanismos visíveis de fratura, como fratura das fibras, fratura da matriz, descolamento fibra/matriz ou delaminação (Figura 5).

As curvas da Figura 3 (a) e (b) mostram que quanto maior a amplitude de tensão ou a tensão média, menor é o número de ciclos à fratura. Observa-se também que os ensaios para a carga de $5000 \mathrm{~N}$ gerou dispersão nos dados. Muito provavelmente alguns mecanismos de danos se ativaram prematuramente. É bem evidenciada a influência da amplitude de tensão no número de ciclos à fratura do material, fazendo com que ao aumentar a amplitude de tensão o número de ciclos a fratura diminua.

\footnotetext{
* Contribuição técnica ao $69^{\circ}$ Congresso Anual da ABM - Internacional e ao 14ํㅡㄹ ENEMET - Encontro Nacional de Estudantes de Engenharia Metalúrgica, de Materiais e de Minas,21 a 25 de julho de 2014, São Paulo, SP, Brasil.
} 

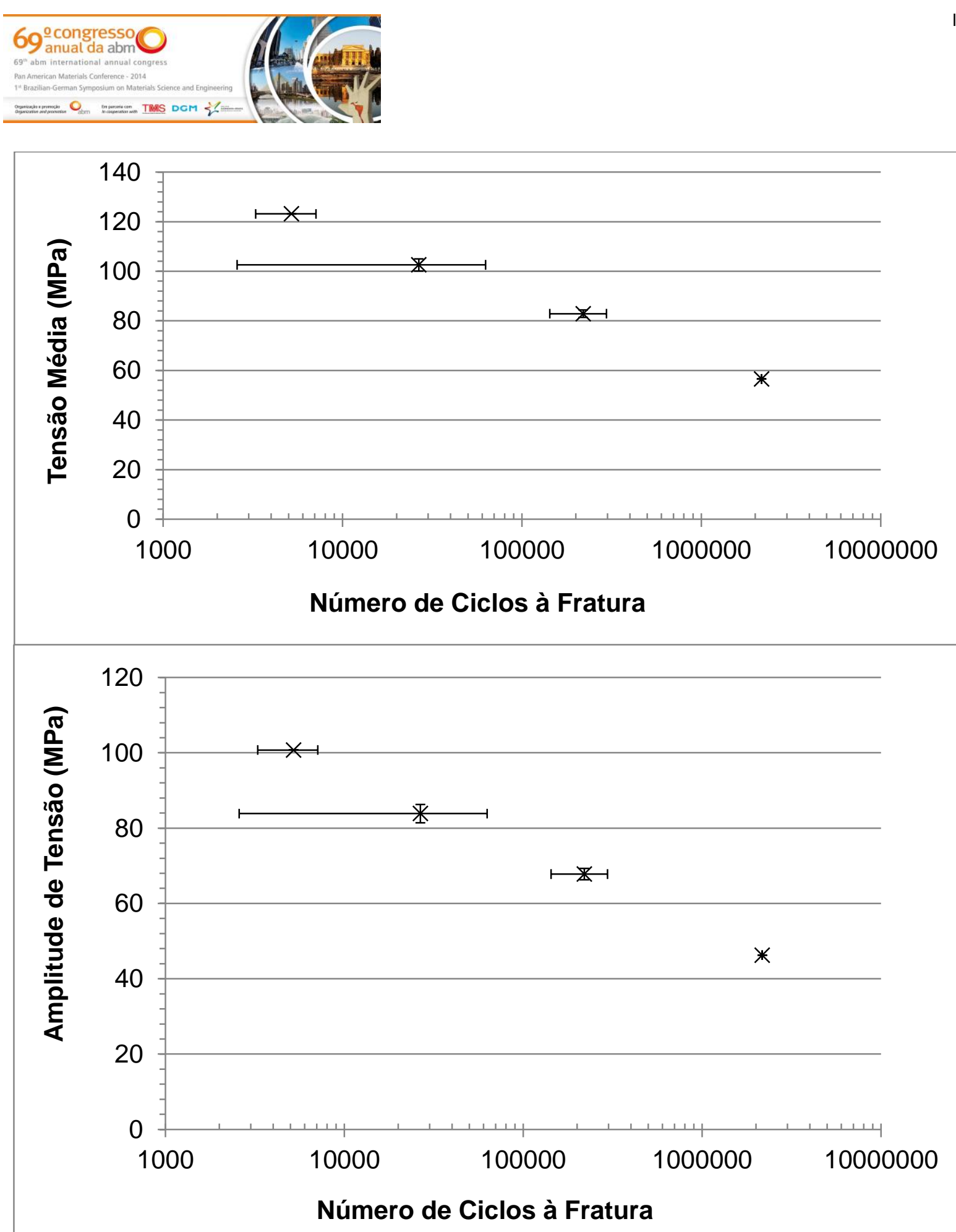

Figura 3. (a) Curva de Tensão Média (MPa) em função do número de ciclos à fratura, (b) curva de Amplitude de Tensão ( $\mathrm{MPa}$ ) em função do número de ciclos à fratura, com barras de erro indicando o desvio padrão dos ensaios.

Na Figura 4, onde foi realizado um ensaio para as cargas de $3000 \mathrm{~N}$ (máxima) e $300 \mathrm{~N}$ (mínima) a $10 \mathrm{~Hz}$, percebe-se que o ensaio estabilizou após aproximadamente 1100 ciclos e a tensão máxima em aproximadamente $105 \mathrm{MPa}$ e a mínima em $10 \mathrm{MPa}$. Podem-se notar as diversas paralizações do ensaio devido ao grande número de ciclos obtidos para estes valores de carregamentos cíclicos aplicados, no entanto, as paralizações e retomadas não afetam significativamente a resposta final.

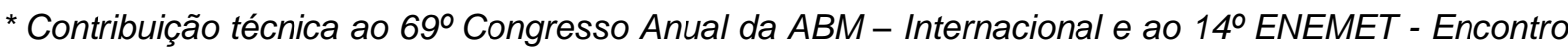
Nacional de Estudantes de Engenharia Metalúrgica, de Materiais e de Minas,21 a 25 de julho de 2014, São Paulo, SP, Brasil.
} 


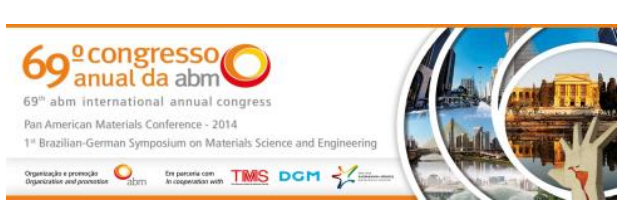

Tabela 2. Dados obtidos dos ensaios de fadiga com controle por tensão para uma freqüência de 10 $\mathrm{Hz}$ e $\mathrm{R}=0,1$

\begin{tabular}{|c|c|c|c|c|c|c|c|}
\hline Amostra & $\mathrm{N}^{\circ}$ Ciclos & $\begin{array}{c}\text { Tensão } \\
\text { Máxima } \\
(\mathrm{MPa})\end{array}$ & $\begin{array}{c}\text { Tensão } \\
\text { Mínima } \\
(\mathrm{MPa})\end{array}$ & $\begin{array}{c}\text { Amplitude } \\
\text { de } \\
\text { Tensão } \\
(\mathrm{MPa})\end{array}$ & $\begin{array}{c}\text { Tensão } \\
\text { Média } \\
(\mathrm{MPa})\end{array}$ & $\begin{array}{c}\text { Deformação } \\
\text { Média }\end{array}$ & $\begin{array}{c}\text { Amplitude } \\
\text { de } \\
\text { Deformação }\end{array}$ \\
\hline 1 & 4.503 & 223,96 & 22,40 & 100,78 & 123,18 & 0,0145 & 0,0040 \\
\hline 2 & 7.361 & 223,80 & 22,38 & 100,71 & 123,09 & 0,0133 & 0,0068 \\
\hline 3 & 3.723 & 223,86 & 22,39 & 100,74 & 123,13 & 0,0138 & 0,0073 \\
\hline 4 & 2.592 & 182,50 & 18,50 & 82,00 & 100,50 & 0,0233 & 0,0035 \\
\hline 5 & 8.960 & 191,42 & 19,14 & 86,14 & 105,28 & 0,0114 & 0,0029 \\
\hline 6 & 68.184 & 185,35 & 18,53 & 83,41 & 101,94 & 0,0096 & 0,0054 \\
\hline 7 & 215.273 & 148,12 & 14,81 & 66,66 & 81,47 & 0,0096 & 0,0028 \\
\hline 8 & 234.073 & 150,38 & 15,04 & 67,67 & 82,71 & 0,0095 & 0,0040 \\
\hline 9 & 136.563 & 153,55 & 15,36 & 69,10 & 84,45 & 0,0090 & 0,0044 \\
\hline 10 & $2.167 .029 *$ & 102,81 & 10,28 & 46,27 & 56,55 & 0,0067 & 0,0047 \\
\hline
\end{tabular}

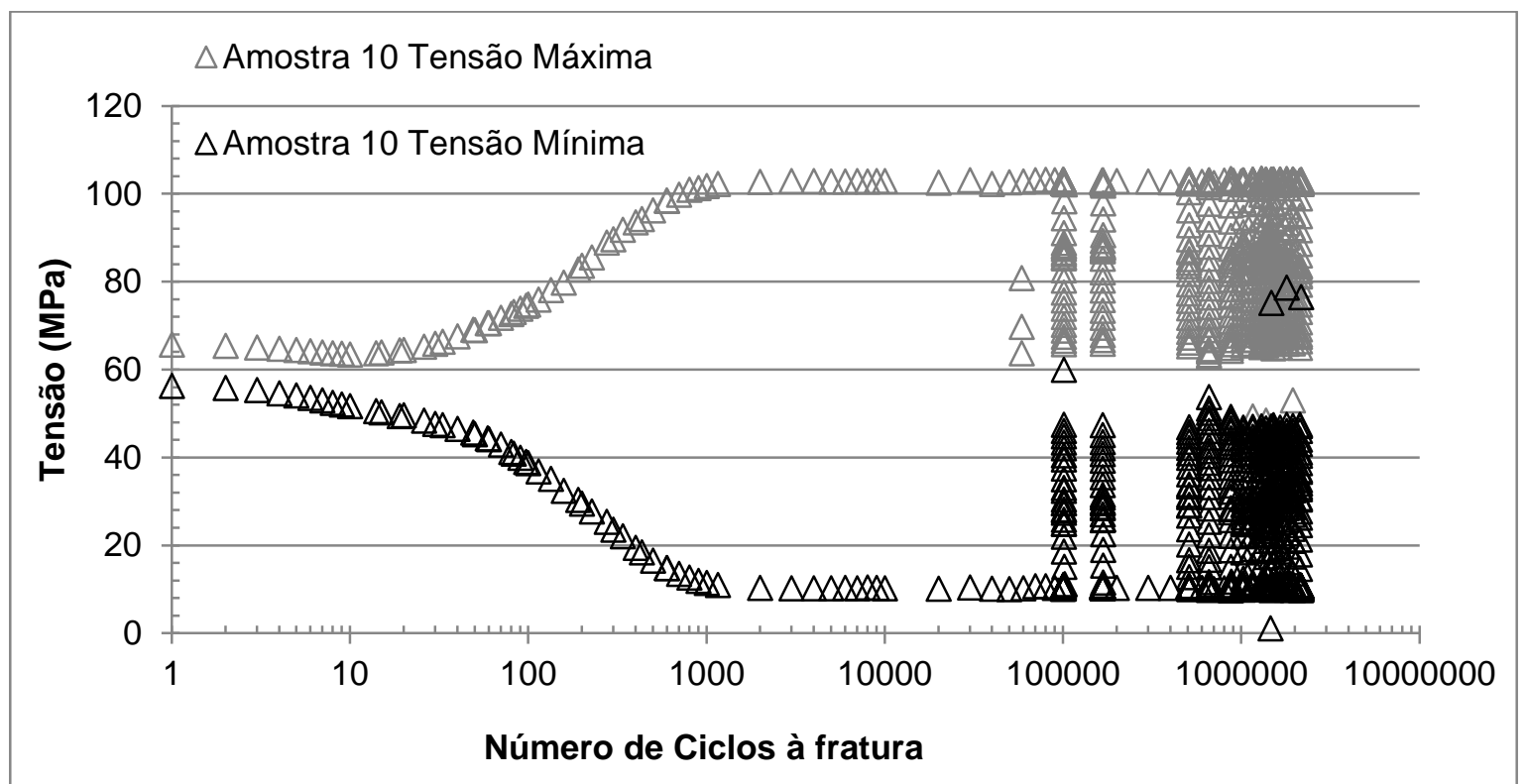

Figura 4. Curva de Tensão máxima e mínima $(\mathrm{MPa})$ em função do número de ciclos à fratura para a amostra ensaiada com carga de $3000 \mathrm{~N}$ (máxima) e 300N (mínima).

Pela Figura 5, observa-se as amostras após fraturarem, são evidenciadas fratura da matriz e da fibra, a maioria com crescimento da trinca na direção transversal na largura do corpo-de-prova, com exceção das amostras 7 e 6 que romperam na lâmina a $45^{\circ}$ da direção transversal da largura, estas teriam pontos de concentração de tensão nessa região gerados na fabricação das amostras, ocasionando menor adesão da matriz com a fibra na silanização. As lâminas a $45^{\circ}$ melhoraram a resposta quanto ao cisalhamento, portanto, se fraturadas significa que foi superada a resistência ao cisalhamento do compósito em questão.

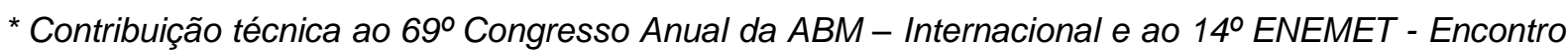
Nacional de Estudantes de Engenharia Metalúrgica, de Materiais e de Minas,21 a 25 de julho de 2014, São Paulo, SP, Brasil.
} 

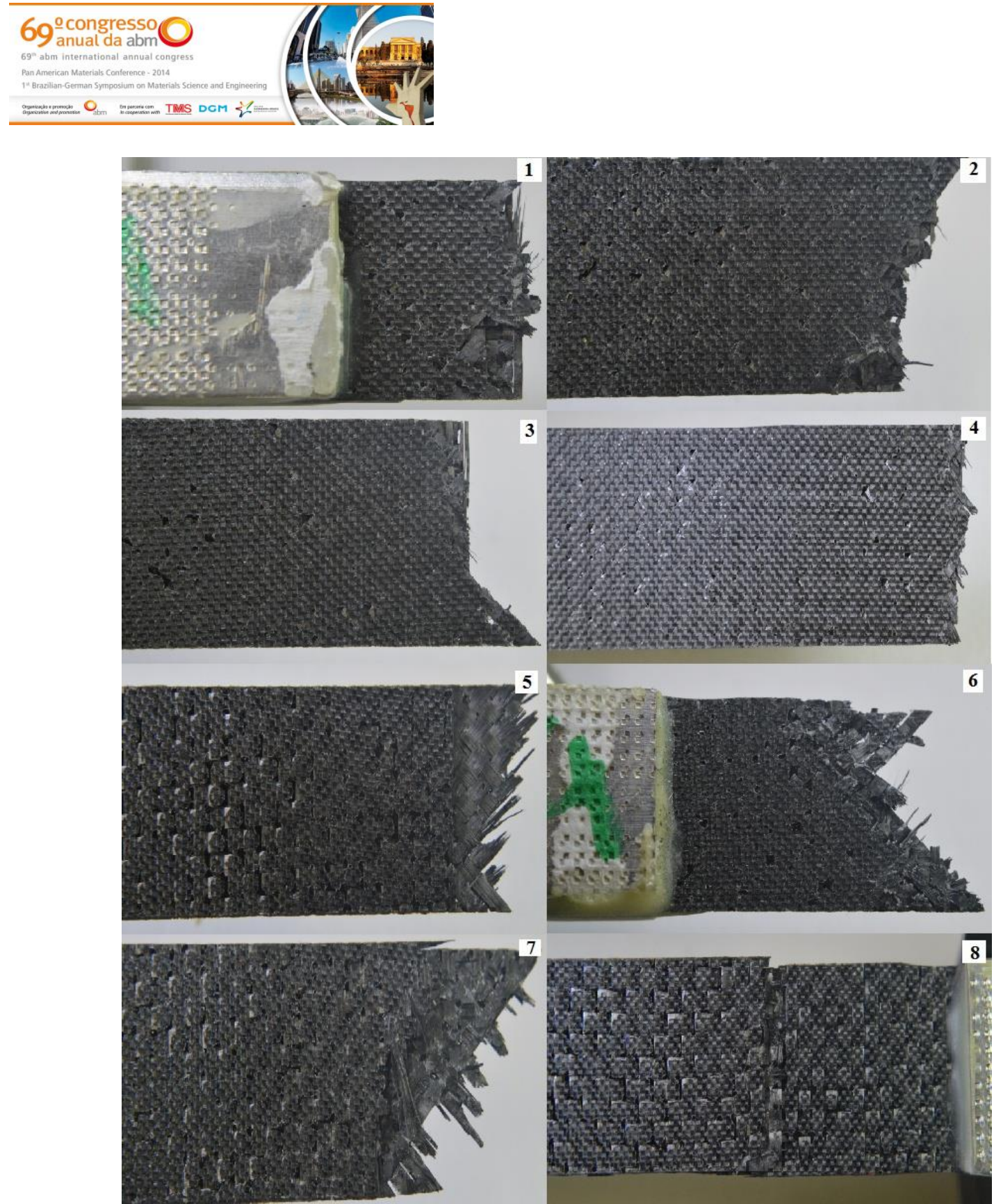

Figura 5. Fratura das amostras, evidenciando fratura da matriz e da fibra.

$\mathrm{Na}$ amostra da Figura 6 ocorreu a delaminação, ocasionando uma separação bem nítida das lâminas na espessura da amostra 9, com carga máxima de $4000 \mathrm{~N}$ e mínima de $400 \mathrm{~N}$. Neste caso, a aderência da interface lâmina-lâmina não foi suficiente para resistir ao carregamento. Esta interface é feita de resina, e em algum momento, a trinca (mostrada na parte superior da Figura 6) ao invés de continuar a propagação e fraturar na direção transversal ao carregamento na largura do corpo de prova, se propagou na direção transversal na espessura. Ou seja, foi facilitada a propagação entre as lâminas e a aderência entre estas não foi eficaz.

\footnotetext{
* Contribuição técnica ao $69^{\circ}$ Congresso Anual da ABM - Internacional e ao 14ํㅡㄹ ENEMET - Encontro Nacional de Estudantes de Engenharia Metalúrgica, de Materiais e de Minas,21 a 25 de julho de 2014, São Paulo, SP, Brasil.
} 


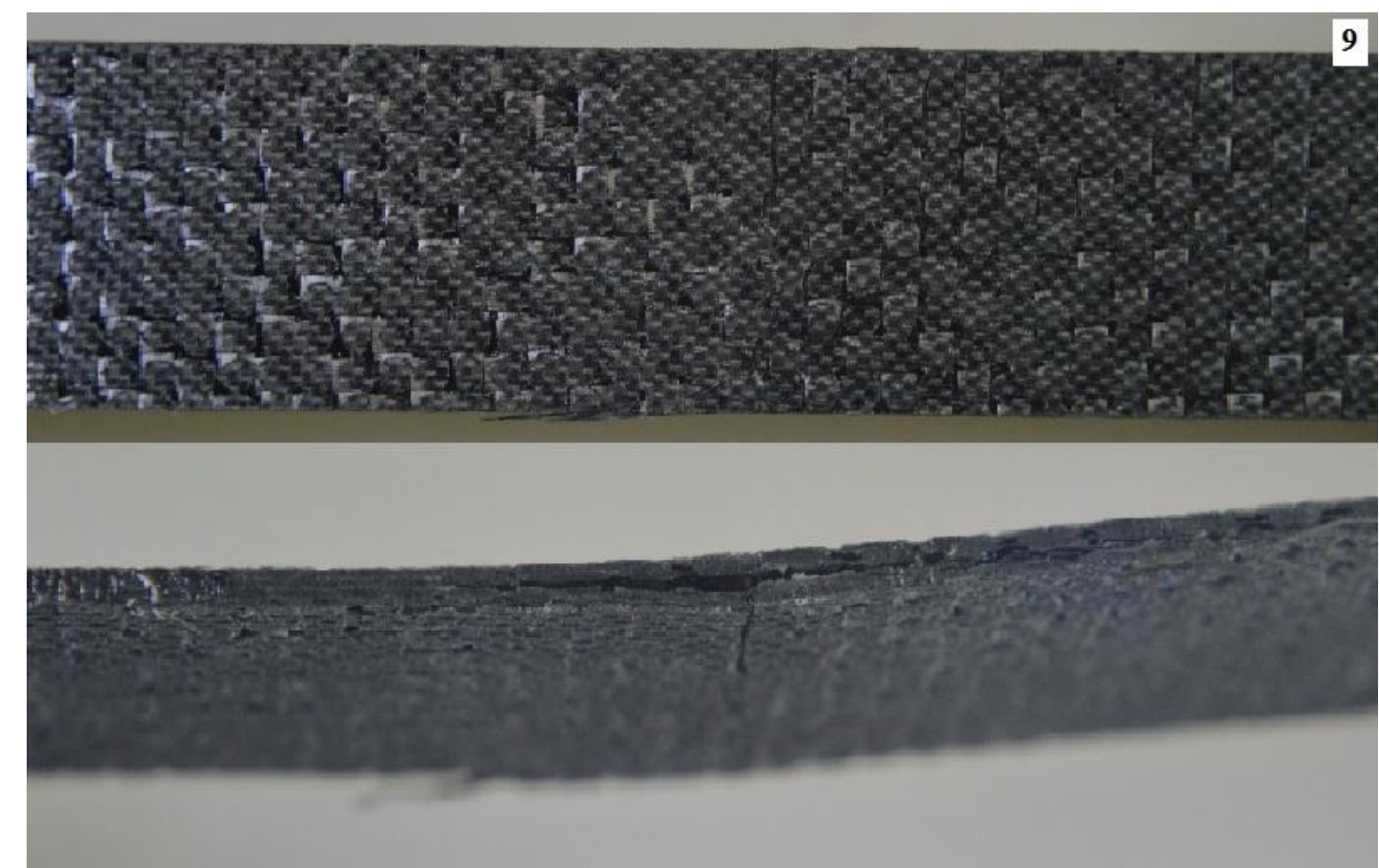

Figura 6. Delaminação da amostra 9, com carga máxima de $4000 \mathrm{~N}$ e mínima de $400 \mathrm{~N}$, freqüência de $10 \mathrm{~Hz}$, na parte superior, a seção longitudinal e na parte inferior, a seção transversal na espessura.

Na Figura 7 observa-se a amostra 1, nas fractografias da seção longitudinal e transversal onde é possível visualizar:

1) Marcas na resina das fibras arrancadas (descolamento) e parte de resina arrancada que mostra perfeitamente a forma do tecido, a seta azul indicada na figura evidencia uma bolha de ar (superfície lisa) que causa uma região sem aderência e com propriedades mecânicas reduzidas nessa região.

2) Fibras ainda bem embebidas de resina e fibras fraturadas.

3) Vazios pelo arracamento das fibras, fibras fraturadas e bolha de ar na resina representada pela seta azul, que indica problemas na cura da resina epóxi.

4) Diversas orientações da fratura e das lâminas do compósito.

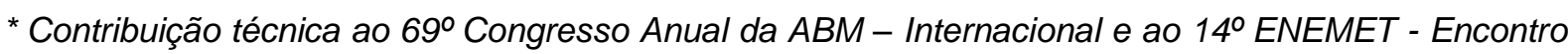
Nacional de Estudantes de Engenharia Metalúrgica, de Materiais e de Minas,21 a 25 de julho de 2014, São Paulo, SP, Brasil.
} 

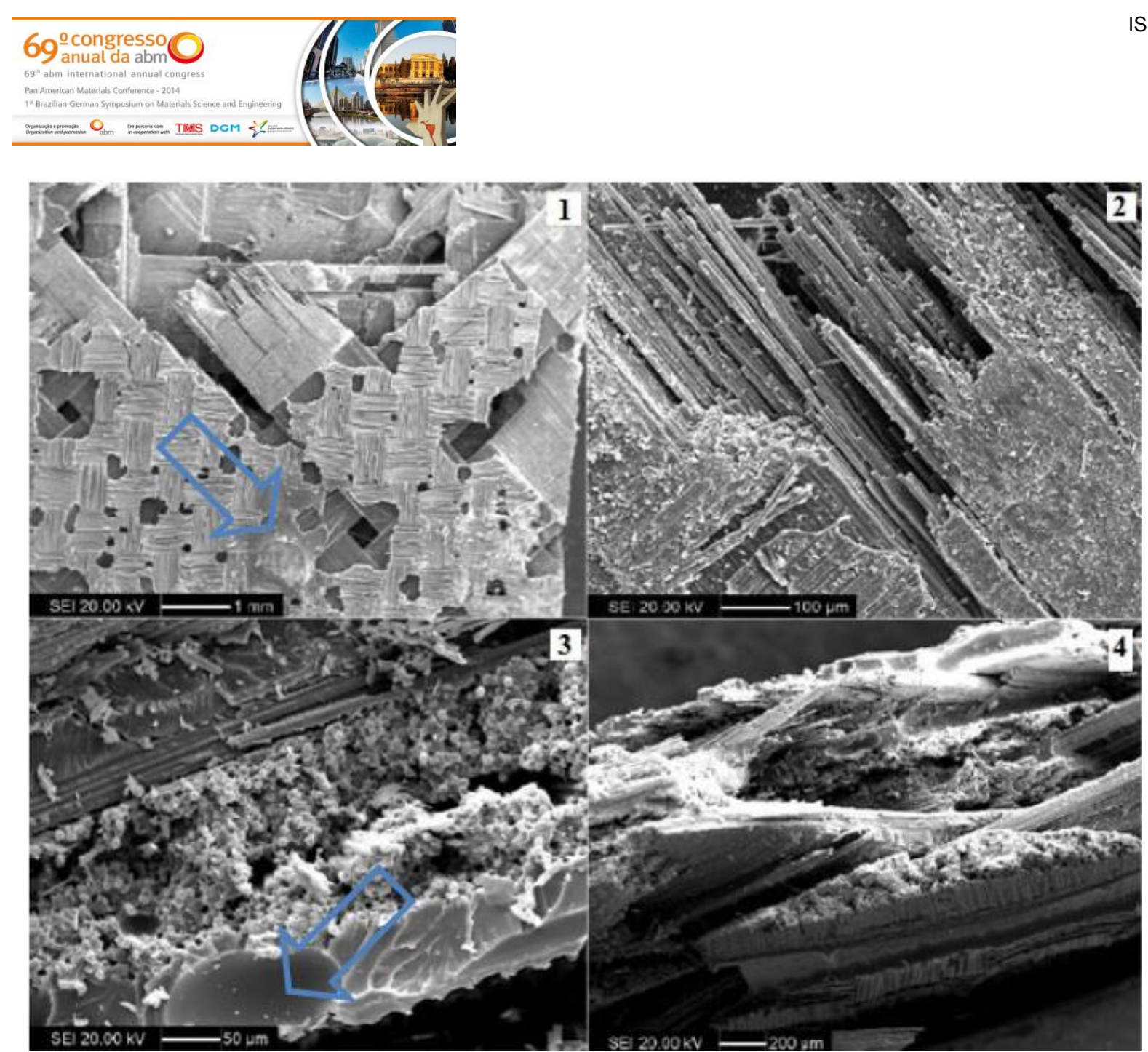

Figura 7. Fractografia da amostra 1 por microscopia eletrônica de varredura, superior seção longitudinal e inferior seção transversal.

Na Figura 8 observam-se fractografias da amostra 6, na seção longitudinal nota-se o descolamento fibra/matriz, o que pode ter ocorrido pela pouca adesão, que ocasiona fraturas por extração das fibras, fissuração da matriz e descolamento entre matriz e fibra. Na seção transversal é possível visualizar a fratura das fibras em diversas orientações, evidenciando nas seções longitudinal e transversal:

1) A seta vermelha indica uma região de arrancamento da resina, e aos lados se observa ainda marcas do tecido de fibras na resina polimérica; a seta azul indica uma bolha de ar, que gera má adesão causada no preparo do material.

2) É possível identificar pela seta azul a fratura das fibras, mas ainda embebidas pela resina polimérica, nessa região a interface foi mais eficiente.

3) Trinca na resina indicada pela seta azul que continuou unida às fibras.

4) Ambas as setas evidenciam bolhas de ar, que causam má adesão no material e diminuem a resistência mecânica.

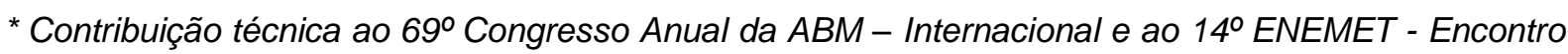
Nacional de Estudantes de Engenharia Metalúrgica, de Materiais e de Minas,21 a 25 de julho de 2014, São Paulo, SP, Brasil.
} 

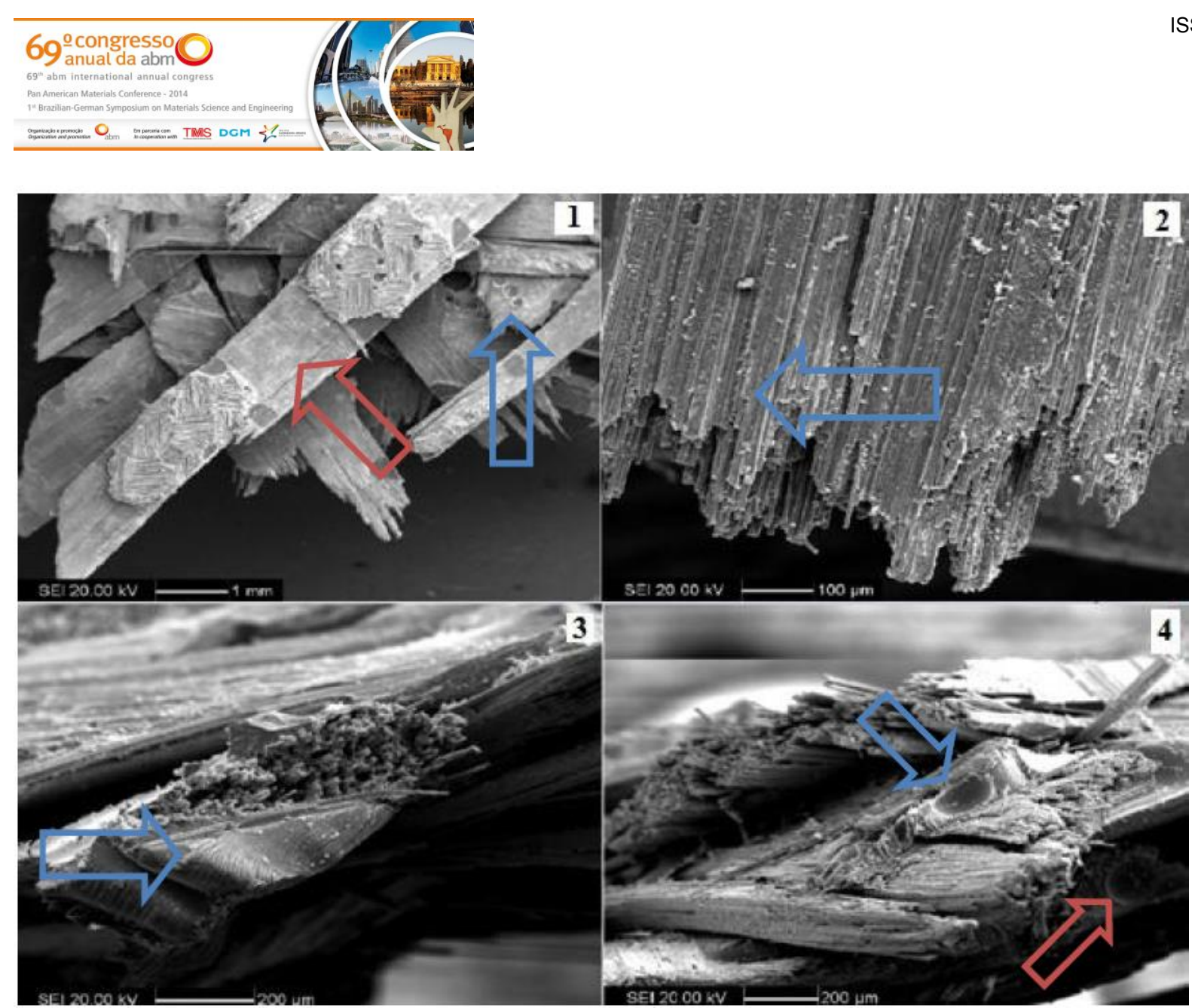

Figura 8. Fractografia da amostra 6 por microscopia eletrônica de varredura, superior seção longitudinal e inferior seção transversal.

$\mathrm{Na}$ Figura 9 observam-se fractografias da amostra 8, pela Figura 5 nota-se que houve delaminação e na fractografia por MEV esse mecanismo é mais visível onde há uma trinca se propagando pela matriz na seção transversal levando à fratura de muitas fibras e, principalmente, provoca a delaminação. As setas azuis indicam regiões de bolhas de ar, sendo que em 2) há uma grande bolha (resina com superfície lisa), que pode ter facilitado a propagação desta trinca, ou seja o defeito de fabricação diminui a resistência da interface entre as lâminas e, então, estas delaminam.

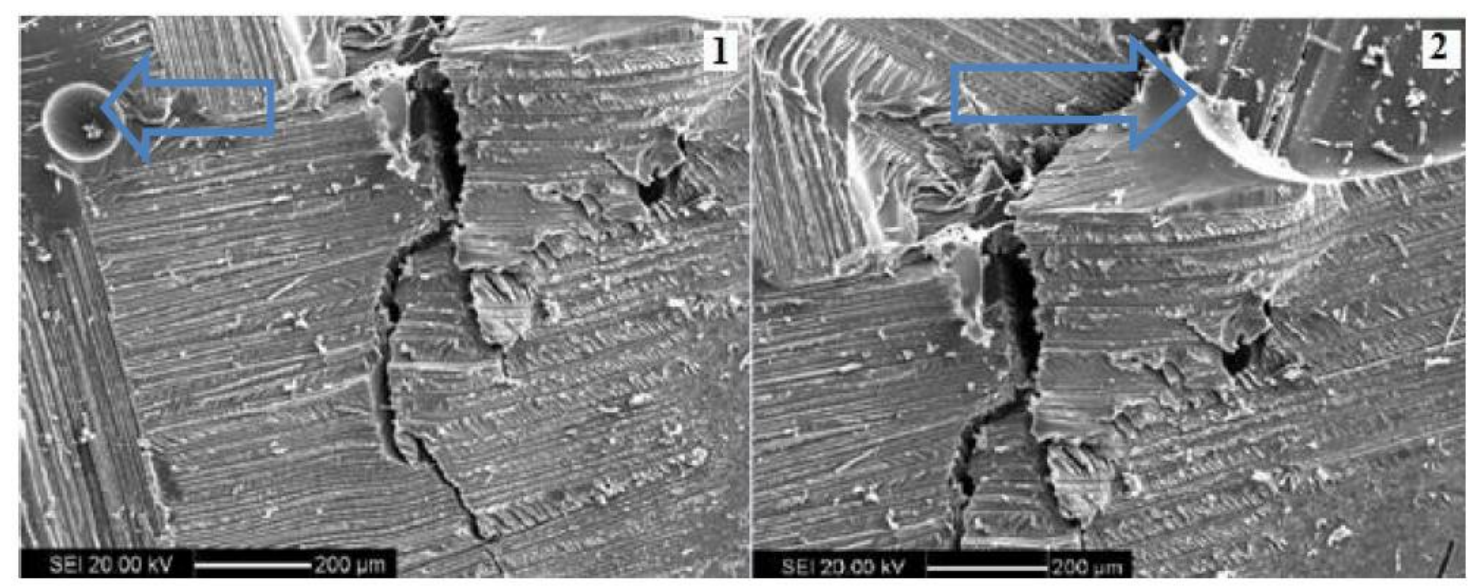

Figura 9. Fractografia da amostra 8 por microscopia eletrônica de varredura, seção longitudinal.

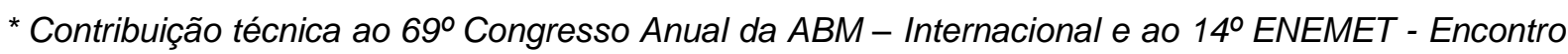
Nacional de Estudantes de Engenharia Metalúrgica, de Materiais e de Minas,21 a 25 de julho de 2014, São Paulo, SP, Brasil.
} 


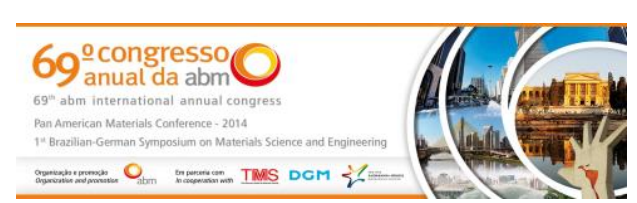

\section{CONCLUSÕES}

Para a configuração de lâminas de $0 \% / 90^{\circ} \pm 45^{\circ}$, o compósito em estudo demonstrou boa resistência à fadiga para cargas cíclicas de tração-tração, por controle de tensão. A tensão para sobreviver a $10^{6}$ ciclos (vida infinita), é de aproximadamente $48,5 \%$ da resistência à tração, considerando a sua resistência à tração de $212 \mathrm{MPa}$ [10]. A análise comtemplou apenas o comportamento do material ao carregamento de tração-tração por controle de tensão e não a obtenção de suas propriedades, pois os ensaios foram realizados com $R=0,1$ e não com $R=-1$ (completamente reversível).

Mesmo tendo paralisações e retomadas nos ensaios devido ao longo tempo de ensaio, não houve mudanças significativas na resposta final (Figura 4). Notou-se que o número de ciclos a fadiga depende da amplitude de tensão, sendo que quanto menor a carga aplicada menor a amplitude de tensão e maior o número de ciclos a fratura e a dependência da tensão média, sendo que quanto menor o número de ciclos a fadiga maior a tensão média, o que sugere uma influência negativa da tensão média na vida em fadiga.

O carregamento cíclico de tração-tração provocou uma mudança substancial no ciclo de histerese desse material, indicando acúmulos progressivos de danos por fadiga, presumivelmente devido à ocorrência de microfissuras na matriz polimérica, mas que não afeta consideravelmente na resistência residual do compósito caso as fibras resistam ao carregamento.

Fratura na matriz, fratura das fibras e descolamento fibra/matriz são os mecanismos de falha dominantes durante a fadiga. Desde que trincas na matriz não sejam prejudiciais às fibras, uma fratura dominante na fibra é a principal falha nesse material. Porém se uma trinca na matriz gerar uma delaminação, a falha no material pode ser inesperada e catastrófica.

A análise por microscopia eletrônica de varredura foi muito eficaz na análise de mecanismos de fratura do compósito em estudo, mostrando que descolamento fibra/ matriz, fratura da matriz e das fibras são predominantes, porém o material apresenta uma considerável resistência à fadiga. Também se evidencia a presença de bolhas de ar no compósito, que ocasionam a diminuição da resistência do material pela falta de aderência, o que significa que o processamento manual deve ser melhorado.

\section{Agradecimentos}

Ao Centro Universitário da $\mathrm{FEl}$, ao Prof ${ }^{\circ}$. Msc. Willian Naville pelo auxílio nos ensaios e na utilização da máquina universal de ensaios, à Prof ${ }^{a}$ Dra. Daniella Caluscio pela colaboração e auxílio nas análises por microscopia eletrônica de varredura e aos técnicos do Laboratório de Materiais (LabMat-FEI).

\section{REFERÊNCIAS}

1 Callister WD. Ciência e engenharia de materiais uma introdução. 7. ed. Rio de Janeiro: LTC; 2008.

2 Levy NF, Pardini LC. Compósitos estruturais: ciência e tecnologia. São Paulo: E. Blücher; 2006.

3 Rezende MC, Costa ML, Botelho EC. Compósitos estruturais: tecnologia e prática. São Paulo: Artliber; 2011.

\footnotetext{
* Contribuição técnica ao $69^{\circ}$ Congresso Anual da ABM - Internacional e ao 14ํㅡㄹ ENEMET - Encontro Nacional de Estudantes de Engenharia Metalúrgica, de Materiais e de Minas,21 a 25 de julho de 2014, São Paulo, SP, Brasil.
} 


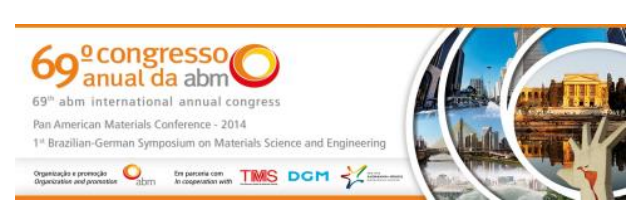

4 Dowling NE. Mechanical behavior of materials - engineering methods for deformation, fracture and fatigue. 3. ed. Estados Unidos. Pearson; 1999.

5 Moraes DVO. Avaliação de propriedades de fadiga de compósito de polipropileno reforçado com fibra de coco [tese de mestrado]. São Bernardo do Campo: Centro Universitário da FEl; 2013.

6 Roesler J, Harders H, Baeker M. Mechanical behaviour of engineering materials: metals, ceramics, polymers, and composites. [S.I.]. Springer;. 2007. p.534.

7 Salerno G. Influência da deformação média na previsão de vida em fadiga de baixo ciclo da liga AA7175-T1 [tese de mestrado]. São José dos Campos: Instituto Tecnológico de Aeronáutica; 2005.

8 Suresh S. Fatigue of materials. 2. ed. Cambridge: Cambridge University; 1998.

9 Rossini MB. caracterização das propriedades elásticas de um material compósito laminado [trabalho de conclusão de curso]. São Bernardo do Campo: Centro Universitário da FEl; 2012.

10 American Society for Testing and Materials. ASTM D3479/D3479M-96: Standard Test Method for Tension-Tension Fatigue of Polymer Matrix Composite Materials. West Conshohocken; 2007.

11 American Society for Testing and Materials. ASTM D3039/D3039M-08: Standard Test Method for Tensile Properties of Polymer Matrix Composite Materials. West Conshohocken; 2008.

* Contribuição técnica ao 69ำ Congresso Anual da ABM - Internacional e ao 14ํㅡㄹ ENEMET - Encontro Nacional de Estudantes de Engenharia Metalúrgica, de Materiais e de Minas,21 a 25 de julho de 2014, São Paulo, SP, Brasil. 